A n American Heart Association scientific statement on secondary prevention of coronary heart disease (CHD) in the elderly pointed out that at necropsy $50 \%$ of elderly women and $70-80 \%$ of elderly men have obstructive coronary artery disease. ${ }^{1}$ Moreover, in the USA, the prevalence of CHD over the age of 75 years is $2.2 \%$ for men and $1.3 \%$ for women. This sizeable problem has been addressed in other reviews; however, they often consider the elderly as all those over 65 years of age and tend to conclude that the secondary prevention of CHD should be the same as in the young and middle aged. These reviews often ignore the fact that the benefit:risk ratio does change with every decade of life. For example, with aspirin both the absolute benefits and absolute risks are greater at age 60-69 than age 50-59. Moreover, although there is an extensive literature suggesting, for example, that blood pressure and serum cholesterol may be safely lowered up to the age of 75-79 years, with considerable benefit and little increase in risk, the problem remains as to whether the benefits will outweigh the risks at older ages.

These anxieties arise from two main sources: firstly, there is little evidence from randomised controlled trials to guide our decisions in the very elderly (over 80s); and secondly they differ in many ways from younger subjects. Table 1 lists some differences in major and minor categories. The list is far from complete. Pharmacological treatment or lifestyle changes may be inappropriate in the demented patient, weight loss is more often a problem than a therapeutic goal, and dietary change may be resisted as may the standard exercise regimens. If the patient has so many problems you do not know which to address first, the prescription of a drug for secondary prevention may not be the place to start. Nevertheless there are patients without serious comorbidity, with good cognitive functioning, and who do not wish to have another cardiac ischaemic episode. We must decide what to advise these patients. This article considers strategies applicable to the chronic treatment of a patient with established CHD and does not address the issue of treatment in the acute situation.

\section{LIFESTYLE CHANGES}

Table 2 lists lifestyle changes that could be advised at different ages. The suggestions for the elderly and very elderly are almost devoid of any evidence base but probably reflect the advice given (if any) by practitioners. We will consider the items in order.

\section{Smoking}

The advantages of stopping smoking are fairly immediate in terms of CHD prevention, and the risks of a fire, especially in bed, are almost certainly reduced. Within one year of stopping smoking, patients over the age of 65 who have undergone coronary artery bypass graft (CABG) surgery will have a reduced incidence of death of nearly $40 \%{ }^{2}$ Smoking increases blood pressure (at least while smoking) by increasing peripheral vascular resistance, and also increases heart rate, impairs flow mediated dilatation of arteries, increases tendency to clotting, and reduces high density lipoprotein (HDL) cholesterol. ${ }^{3}$ Strong advice and nicotine replacement therapy should be the rule, although gum based therapy will be inappropriate for those with dentures. Over the age of 80 the strategy has only one + in table 2 as many of the very elderly have outlived their friends, are lonely, and will miss the lifetime "comfort" of smoking. Moreover they are unlikely to live the 15 years required to lower their lung cancer risk to normal but stand to gain in the stabilisation or improvement in respiratory symptoms and from gains in other (mainly peripheral) vascular disease.

Professor Christopher J Bulpitt Care of the Elderly, Division of Medicine, Imperial College School of Medicine, Du Cane Road, London W12 OHS, UK; c.bulpit+@imperial.ac.uk

\section{Weight loss}

Being overweight is a good prognostic sign in the very elderly and advice to lose weight should possibly be restricted to the obese. 


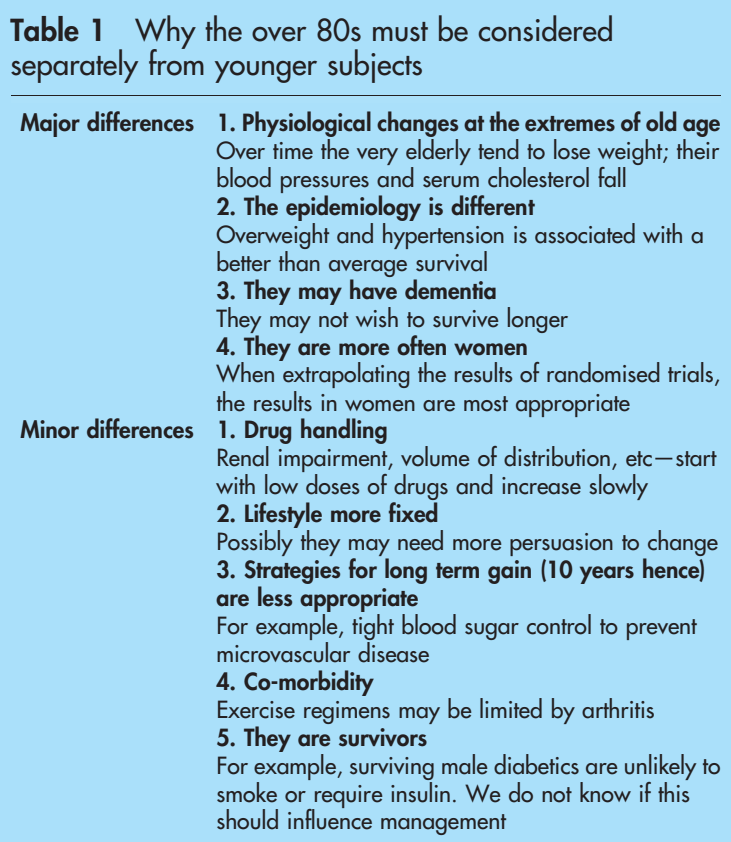

Table 1 Why the over 80 s must be considered separately from younger subjects

Major differences 1. Physiological changes at the extremes of old age Over time the very elderly tend to lose weight; their blood pressures and serum cholesterol fall 2. The epidemiology is different Overweight and hypertension is associated with a better than average survival

3. They may have dementia

They may not wish to survive longer 4. They are more often women When extrapolating the results of randomised trials, the results in women are most appropriate

Minor differences 1. Drug handling Renal impairment, volume of distribution, etc-start with low doses of drugs and increase slowly 2. Lifestyle more fixed Possibly they may need more persuasion to change 3. Strategies for long term gain (10 years hence) are less appropriate

For example, tight blood sugar control to prevent microvascular disease

4. Co-morbidity

Exercise regimens may be limited by arthritis 5. They are survivors

For example, surviving male diabetics are unlikely to smoke or require insulin. We do not know if this should influence management

\section{Exercise}

The elderly should certainly exercise if they can. The recommendation in the very elderly is only lowered to one + because of the danger of falls which should anyway be reduced by a successful exercise programme.

\section{Dietary advice}

My personal bias, shared by some colleagues, is that dietary changes may be more difficult to implement in the very elderly.

\section{Saturated fat}

There is some evidence that total cholesterol is lowered by diet more in men than in women. ${ }^{4}$

\section{Salt reduction}

In one trial of 50 elderly subjects, average age 67 years, systolic blood pressure was reduced by $9 \mathrm{~mm} \mathrm{Hg}$ and diastolic by $6 \mathrm{~mm} \mathrm{Hg}$ by a combination of fish oil and low sodium diet. ${ }^{5}$

Table 2 Lifestyle changes to be advised for secondary prevention of CHD

\begin{tabular}{|c|c|c|c|}
\hline & \multicolumn{3}{|c|}{ Age (years) } \\
\hline & $<65$ & $65-79$ & $80+$ \\
\hline Stop smoking & ++ & ++ & + \\
\hline \multicolumn{4}{|l|}{ Lose weight } \\
\hline $\mathrm{BMI}>25-29$ & ++ & + & - \\
\hline $\mathrm{BMI} \geqslant 30$ & ++ & ++ & ++ \\
\hline Exercise & ++ & ++ & + \\
\hline \multicolumn{4}{|l|}{ Dietary changes } \\
\hline Less saturated fat & ++ & ++ & + \\
\hline Less salt† & ++ & ++ & + \\
\hline More fish & ++ & + & $?$ \\
\hline Reduce alcohol intake to 1-3 drinks/day & ++ & + & $?$ \\
\hline \multicolumn{4}{|c|}{$\begin{array}{l}\text { The more " }+ \text { " symbols, the stronger the advice. } \\
\text { tln presence of hypertension (in presence of heart failure this should be } \\
\text { advised at all ages). } \\
\text { BMl, body mass index }\left(\mathrm{kg} / \mathrm{m}^{2}\right) \text {. }\end{array}$} \\
\hline
\end{tabular}

More fish

In addition to the experimental evidence of an interaction between salt reduction and fish oil consumption mentioned above, an observational study on 515 subjects with coronary artery disease (average age 61 years) found that consumption of fish was associated with a borderline significant $40-50 \%$ reduction in death. ${ }^{6}$

Alcohol

Alcoholic cardiomyopathy is not common in the community and therefore most studies find that all levels of alcohol intake are associated with a reduction in cardiac deaths, but high intakes are associated with an increase in noncardiovascular mortality. It would therefore appear reasonable for those elderly subjects taking $1-3$ drinks per day to continue to do so and those on higher intakes to reduce to those levels in order to optimise their chances of survival. Little is known about alcohol consumption in the very elderly except that they drink less than younger subjects.

\section{PHARMACEUTICAL TREATMENTS}

Table 3 lists the pharmacological measures that should be considered in the elderly. The evidence is mainly lacking in the very elderly.

\section{Aspirin}

Table 4 presents the arguments for and against aspirin use in secondary prevention in the elderly. The antiplatelet trialists collaboration reported a $4.5 \%$ absolute reduction in risk of a vascular event in high risk subjects over the age of 65 years. ${ }^{7}$ The patients received a number of different antiplatelet agents but the results were confirmed for aspirin alone and for both men and women. The number needed to treat (NNT) to avoid one vascular event was about 20 over two years, and these results almost certainly apply to the secondary prevention of CHD although the "high risk" group included transient ischaemic attacks and strokes. It has also been suggested that aspirin will prevent dementia, and possibly colon cancer. ${ }^{8}$ If true these would be of major importance in the elderly.

On the down side there are the risks of treatment. These have been reported as negligible, ${ }^{9}$ but over the age of 70 years a $3 \%$ absolute risk of gastrointestinal bleeding has been reported. ${ }^{10}$ The risk of a haemorrhagic stroke is increased by a relative risk of $40 \%$. This is important as the incidence of cerebral haemorrhage increases notably in the very elderly. The elderly also tend to become anaemic while taking aspirin. ${ }^{10}$

Despite the above risks the current consensus is that aspirin should be offered to the elderly for the secondary prevention of CHD. A dose range of $75-325 \mathrm{mg}$ is supported

Table 3 Pharmacological measures for the secondary prevention of ischaemic heart disease at different ages

\begin{tabular}{llll}
\hline & \multicolumn{3}{l}{ Age (years) } \\
\cline { 2 - 4 } & $<65$ & $65-79$ & $80+$ \\
\hline Aspirin & ++ & ++ & + \\
$\beta$ Blockers & ++ & + & $?$ \\
ACE inhibitors & ++ & ++ & + \\
Other antihypertensive treatment & ++ & ++ & $?$ \\
Statins & ++ & ++ & $?$ \\
Glycaemic control & ++ & ++ & + \\
\hline \multirow{2}{*}{ ACE, angiotensin converting enzyme. } & & &
\end{tabular}


Table 4 Arguments for and against aspirin use in secondary prevention of CHD over age $65-70$ years

For Against

1. $4.5 \%$ absolute risk reduction $\quad$ 1. $3 \%$ absolute risk of increase

in vascular events ${ }^{7} \quad$ in gastric bleeding

$\begin{array}{ll}\text { 2. Possible reduction in incidence } & \text { 2. } 40 \% \text { relative risk increase }\end{array}$

of dementia

3. Possible reduction in

gastrointestinal cancer $^{8}$

in haemorrhagic stroke

3. Development of anaemia ${ }^{10}$

by the evidence. If aspirin is not tolerated, clopidogrel may be substituted. This drug is associated with a slightly lower incidence of vascular events than aspirin when used for CHD prevention and a similar incidence of overall haemorrhagic events. However, clopidogrel is associated with fewer gastrointestinal haemorrhagic events ( $2 \%$ over nearly two years) than aspirin $(2.7 \%){ }^{11}$

\section{ß Adrenoceptor blockers}

Rich performed a meta-analysis of three of the placebo controlled trials of $\beta$ blockers post-myocardial infarction (MI) and found a $6 \%$ reduction in total mortality at age 65-75 years compared with a $2.1 \%$ reduction at younger ages. ${ }^{12}$ Dornbrook-Lavender and colleagues have described this as a clear demonstration of increased efficacy in the elderly. ${ }^{13}$

With these obvious benefits and an NNT of only about 20 to save one death over two years ( similar to that of aspirin for vascular events), why are a large number of the elderly not offered $\beta$ blockers? In one study the chance of a patient over the age of 85 years receiving a $\beta$ blocker was reduced by $74 \%$ in comparison with subjects under the age of $55 .{ }^{14}$ Although there are important contraindications to $\beta$ blockers that increase with age (asthma, chronic obstructive pulmonary disease, peripheral vascular disease, and diabetics at risk of hypoglycaemia), it is unlikely that these conditions explain the under-utilisation of these drugs. However, initial concerns about a serious reduction in exercise tolerance and precipitation of heart failure have been somewhat removed by the use of $\beta$ blockers in heart failure. These drugs should be employed but with careful monitoring for postural hypotension, pronounced bradycardia, and bronchospasm. The trial evidence, however, does not exist for subjects over the age of 80 years.

\section{Angiotensin converting enzyme inhibitors}

Dornbrook-Lavender and colleagues quote four trials showing increased efficacy from angiotensin converting enzyme (ACE) inhibition for post-MI patients aged over 65 years and up to 80 years. ${ }^{13}$ One trial, GISSI- $3,{ }^{15}$ had $27 \%$ of subjects over 70 years of age. The absolute reduction in these elderly subjects was $3.5 \%$ for a combined mortality and cardiovascular end point. The number needed to treat for six weeks was therefore about 30. The other three trials suggested reductions in absolute risk for mortality (all ages) of 4\%, 5\%, and $6 \%$, leaving no doubt of the benefits. Moreover the risks are infrequent apart from a dry cough in up to $20 \%$. In the event of this symptom an angiotensin receptor blocker (ARB) may be substituted. The incidence of angioneurotic oedema is very rare and renal dysfunction $(<2 \%)$ is low with ACE inhibitors.

In summary all patients should be offered an ACE inhibitor for the secondary prevention of CHD. The only limiting factors are hypotension and postural hypotension. Interestingly, in the GISSI-3 trial $31 \%$ of the subjects were on $\beta$ blockers and $84 \%$ were on aspirin. ${ }^{15}$

\section{Other antihypertensive treatment}

It is generally agreed that, in the secondary prevention of CHD, raised blood pressure should be reduced to "normal". The CHD event may not have reduced the blood pressure and the results of antihypertensive trials indicate the benefits to be expected, especially when patients with pre-existing coronary disease are included in the analysis.

The benefits from lowering blood pressure are apparent in both middle aged subjects and the elderly, at least to the age of around 79 years. The recent blood pressure lowering treatment trialists' collaboration ${ }^{16}$ concluded that there were no significant differences in total major cardiovascular events between regimens based on ACE inhibitors, calcium antagonists, diuretics, or $\beta$ blockers. All groups reduced events and the reductions were directly related to the blood pressure reduction achieved. Six trials against placebo included CHD as one of the entry criteria and three did not. For all nine trials CHD was reduced by both ACE inhibitors $(-20 \%)$ and calcium channel blockers (CCBs) $(-22 \%)$, whereas heart failure was not reduced by CCBs $(+21 \%)$. Stroke was reduced by an average of $28 \%$ with ACE inhibitors and 38\% with CCBs. Staessen and colleagues also performed a metaanalysis and concluded that the better the blood pressure control, the better the results and that "CCBs might be especially effective in stroke prevention" ${ }^{\prime 17}$ In conclusion, the most important objective is to reach goal blood pressure, possibly a systolic pressure $<135 \mathrm{~mm} \mathrm{Hg}$. Obviously in the secondary prevention of CHD, $\beta$ blockers and ACE inhibitors should be employed as first line treatment, and diuretics and ARBs could be employed as second line. Anxieties about both CCBs and doxazosin precipitating heart failure may limit their use to third line treatment; however, if they are needed to control systolic pressure they should be employed. Diastolic blood pressure is less of an issue in the elderly, as it tends to fall over the age of 50-60 years, but if raised it should still be reduced to below $85 \mathrm{~mm} \mathrm{Hg}$. The blood pressure should be monitored in the standing position as postural hypotension must be detected and treatment adjusted accordingly.

The problem lies in the secondary prevention of CHD by lowering blood pressure in those over 80 years of age. These subjects are more prone to postural hypotension, postprandial hypotension, electrolyte disturbances, and renal failure, and it is possible that these problems outweigh the benefits. A meta-analyses of the over 80 s subgroups in seven clinical trials, five of which were double blind, showed that active treatment reduced stroke by $33 \%(p=0.01)$, major coronary events by an average of 22\% (not significant (NS)), and heart failure by $39 \%(p=0.01)$, but that cardiovascular deaths were not reduced. For the five double blind trials there was tendency to an $11 \%$ increase in cardiovascular death (NS) and a $14 \%$ increase in total mortality $(\mathrm{p}=0.05)$. Only $5 \%$ of the subjects in the meta-analysis had had a previous MI. ${ }^{18}$

The recently reported hypertension in the very elderly pilot trial (HYVET-PILOT) supported this dilemma. ${ }^{19}$ Active treatment reduced stroke events by 53\% ( $\mathrm{p}=0.02)$, but tended to increase cardiovascular death and total mortality by $13 \%$ and $23 \%$, respectively (NS for both). Again only $3 \%$ of the patients had had a previous MI and the results cannot be expected to represent secondary prevention. Nevertheless for 
Table 5 Advantages and disadvantages of statin treatment in the elderly for the secondary prevention of CHD

\begin{tabular}{|c|c|c|c|}
\hline & \multicolumn{3}{|l|}{ Age } \\
\hline & $\begin{array}{l}\text { 40-80 years } \\
\text { MRC/BHF }\end{array}$ & $\begin{array}{l}\text { 70-80 years } \\
\text { MRC/BHF }\end{array}$ & $\begin{array}{l}70-82 \text { years } \\
\text { PROSPER }{ }^{21}\end{array}$ \\
\hline \multicolumn{4}{|l|}{ Advantages } \\
\hline \multicolumn{4}{|l|}{ Change in coronary } \\
\hline Change in stroke events & $-25 \%$ & - & $\begin{array}{l}-19 \% \\
+3 \%\end{array}$ \\
\hline Disadvantages & & & \\
\hline Development of & $0.06 \%$ & - & $<0.01 \%$ \\
\hline \multirow{2}{*}{$\begin{array}{l}\text { Development of } \\
\text { disturbed liver function } \\
\text { Increase in cancer } \\
\text { incidence }\end{array}$} & $0.18 \%$ & - & $<0.01 \%$ \\
\hline & No & - & $+25 \%$ \\
\hline
\end{tabular}

MRC/BHF, Medical Research Council/British Heart Foundation; PROSPER, pravastatin in elderly individuals at risk of vascular disease.

every stroke saved (fatal or non-fatal) there was one excess non-stroke death. The HYVET main trial is currently being performed to determine the risks and benefits of lowering blood pressure in the over 80 s.

\section{Statins}

The Medical Research Council/British Heart Foundation (MRC/BHF) heart protection study randomised 20536 high risk individuals to $40 \mathrm{mg}$ simvastatin daily or placebo. ${ }^{20}$ Nonfasting total cholesterol had to be above $3.5 \mathrm{mmol} / \mathrm{l}$. Sixty five per cent had some history of coronary disease and 5806 were 70-80 years old at entry (the others were aged between 40-69 years).

In the total group coronary events were reduced by $27 \%$ and stroke events by $25 \%$. Overall $0.06 \%$ developed myopathy, $0.18 \%$ developed disordered liver function, and no overall excess of cancer was found in the simvastatin group. The results were reported by age group for first major vascular events. These were reduced by about $27 \%$ at age $40-$ 69 years and by approximately $22 \%$ at age $70-80$ years. For first coronary event the reductions were $20 \%$ for age $70-80$ years and 35\% for age 40-64 years.

Table 5 gives the advantages and disadvantages of statin treatment. The results for age 70-80 years are derived from the MRC/BHF trial. ${ }^{20}$ Clear benefits were apparent in reducing coronary events at this age. The incidence of cancer events was not increased, apart from a very small anxiety over non-melanoma cancers of the skin, and therefore the results have not been presented by age. At age 70-79 years, the benefit of treatment greatly outweighed any disadvantages.

Only one trial gives any information relevant to the over 80s. The pravastatin in elderly individuals at risk of vascular disease (PROSPER) trial included patients from age 70-82 years with pre-existing vascular disease. ${ }^{21}$ Their total cholesterol had to be between $4.0-9.0 \mathrm{mmol} / \mathrm{l}$ and triglycerides $<6.0 \mathrm{mmol} / \mathrm{l}$. The patients were randomised to $40 \mathrm{mg}$ pravastatin daily or placebo. The subjects randomised in PROSPER totalled 5804 and were slightly older (average age 75.3 years) than the $70-80$ year age groups in the MRC/BHF trial. The PROSPER trial lasted for three years and the MRC/ BHF trial for five years. Although coronary events were reduced by $19 \%$ in the PROSPER trial there was no evidence for stroke reduction (hazard ratio 1.03, 95\% confidence interval 0.81 to 1.31$)$. Cancer incidence increased with pravastatin by $25 \%$. Thus this trial failed to show benefits in terms of stroke reduction and raised the possibility of an increase in cancer events. It is therefore possible that in the very elderly, the benefits of statin treatment would not outweigh the disadvantages and randomised trials should be directed to the over 80s. Such a trial will include a preponderance of women. In the PROSPER trial the primary end point was reduced by $23 \%$ in men but only by $4 \%$ in women. Nevertheless both men and women under the age of 80 should receive statin treatment for the secondary prevention of CHD. The NNT from the MRC/BHF trial to prevent a first vascular event was 18 over five years.

\section{Glycaemic control}

The incidence of CHD in diabetic patients is very high and we must discuss the need for tight glycaemic control in the secondary prevention of CHD. However, there are no randomised trials of tight glycaemic control in the secondary prevention of CHD. The UK prospective diabetes study (UKPDS) trial was a primary prevention study and excluded patients with recent cardiac problems. ${ }^{22}$ Nevertheless the trial produced the results shown in table 6. Over 10 years, in patients initially 25-65 years of age, there were benefits in preventing microvascular disease, although these took about five years to become apparent. Myocardial infarction tended to be reduced by $16 \%$ but was of borderline significance. The treatments, a sulfonylurea or insulin, were associated with hypoglycaemic episodes in $11-37 \%$ per year. These results have been accepted as evidence for tight glycaemic control in subjects with type 2 diabetes, average age 53 years, with many years to live. We need to extrapolate to both the secondary prevention of CHD and to the elderly. It would appear reasonable to employ tight glycaemic control in secondary prevention for the middle aged and young elderly. They have many years to live, will benefit from microvascular prevention, and should be able to cope with episodes of hypoglycaemia. However, it is far from certain that those over the age of 70 and especially over the age of 80 will reap the same advantages and not experience more serious hypoglycaemic episodes. Nevertheless, the UKPDS trial and other studies have emphasised how important it is to lower blood pressure and low density lipoprotein (LDL) cholesterol in diabetics. In the secondary prevention of CHD we should be more willing to lower blood pressure and cholesterol in diabetics than in non-diabetics. This strategy has trial support. ${ }^{23}$ However, the lowering of cholesterol was not supported by the study of a few diabetic subjects in the PROSPER trial, ${ }^{21}$ although subjects with previous CHD and

\begin{tabular}{|c|c|c|}
\hline & \multicolumn{2}{|l|}{ Age } \\
\hline & $25-65$ years & Elderly \\
\hline $\begin{array}{l}\text { Advantages of tight glycaemic control } \\
\text { Prevention of microvascular disease } \\
\text { Prevention of myocardial infarction } \\
\text { Prevention of albuminuria } \\
\text { Prevention of cataract extraction } \\
\text { Disadvantages of tight glycaemic control } \\
\text { Hypoglycaemic episodes }\end{array}$ & $\begin{array}{l}-25 \% \\
-16 \% \\
-33 \% \\
-24 \% \\
+11-37 \% / \text { year }\end{array}$ & $\begin{array}{l}? \\
? \\
? \\
?\end{array}$ \\
\hline
\end{tabular}


diabetes did benefit in the MRC/BHF trial (a 20\% reduction in major coronary event). ${ }^{20}$

\section{CONCLUSION}

This article has not considered the treatment of the complications of CHD, most importantly angina, heart

failure, and atrial fibrillation, nor has it considered the place of angioplasty and CABG. Obviously these are all important areas but are outside the scope of the present article. Nevertheless the important treatments that should be initiated in the secondary prevention of CHD are described, all of which may be initiated by a cardiologist, geriatrician, specialist in general internal medicine, or a general practitioner. The challenge remains to deliver these treatments in the vast majority of patients. Currently we fail to achieve reasonable targets, with a large UK population study reporting that only $65 \%$ of men aged 44 with CHD receive aspirin treatment, and 59\% of women; $49 \%$ of the men and $38 \%$ of the women had been prescribed a statin; and within one year of an MI only $29 \%$ of men and $20 \%$ of women received a $\beta$ blocker. Post-MI $25 \%$ of men and $26 \%$ of women received an ACE inhibitor. ${ }^{24}$ These results refer to the years 2000 and 2001 and hopefully the situation is improving. On the positive side blood pressure was monitored in $89-90 \%$ of patients, cholesterol recorded in $64 \%$ of men and 55\% of women, and body mass index in $34 \%$ of both sexes. All medical and nurse practitioners involved in the care of CHD patients should attempt to institute these measures.

Although I have cast some doubt over how to manage the over 80s with CHD, this should not distract from getting all the younger elderly subjects to make appropriate lifestyle changes, and take aspirin, $\beta$ blockers, ACE inhibitors, and statins as indicated. For the very elderly, the minimum should be the institution of cardiac rehabilitation and antismoking advice, and prescription of antiplatelet and ACE inhibitor treatment.

The author is in receipt of research funding and occasional consultancy fees from the pharmaceutical industry.

\section{REFERENCES}

1 Williams MA, Flegg JL, Ades PA, et al. Secondary prevention of coronary heart disease in the elderly (with emphasis on patients $\geqslant 75$ years of age). An American Heart Association scientific statement from the council on clinical cardiology subcommittee on exercise, cardiac rehabilitation, and prevention. Circulation 2002; 105: 1735-43.

- This statement contains important sections on the management of diabetes and interventional treatment (surgery and angioplasty). The authors also consider psychosocial interventions including social support and physical activity. It provides 94 useful references.

2 Hermanson B, Omenn GS, Kronmal RA, et al. Beneficial six-year outcome of smoking cessation in older men and women with coronary artery disease: results from the CASS registry. N Engl J Med 1998;319:1365-9.

3 Sparrow D, Dawber T. The influence of cigarette smoking on prognosis after first myocardial infarction. J Chronic Dis 1978;31:425-32.

4 Li Z, Otvos JD, Lamon-Fava S, et al. Men and women differ in lipoprotein response to dietary saturated fat and cholesterol restriction. J Nutr 2003; 133:3428-33.

5 Cobiac L, Nestel PJ, Wing LM, et al. Effects of dietary sodium restriction and fish oil supplements on blood pressure in the elderly. Clin Exp Pharmacol Physiol 1991;18:265-8.
6 Erkkila AT, Lehto S, Pyorala K, et al. n-3 fatty acids and 5-y risks of death and cardiovascular disease events in patients with coronary artery disease. Am J Clin Nutr 2003;78:65-71.

7 Antiplatelets Trialist' Collaboration. Collaborative overview of randomised trials of antiplatelets therapy: prevention of death, myocardial infarction, and stroke by prolonged antiplatelet therapy in various categories of patients. BMJ 1994;308:81-106.

8 Sandler RS. Aspirin and other nonsteroidal anti-inflammatory agents in the prevention of colorectal cancer. Important Adv Oncol 1996:123-37.

9 Silagy CA, McNeil JJ, Donnan GA, et al. Diverse effects of low-dose aspirin in a healthy elderly population. Clin Pharmacol Ther 1993;54:84-9.

10 Silagy CA, McNeill JJ, Donnan GA, et al. The PACE pilot study: 12 month results and implications for future primary prevention trials in the elderly (prevention with low-dose aspirin of cardiovascular disease in the elderly). J Am Geriatr Soc 1994;42:643-7.

- This was an important pilot trial testing the feasibility of a randomised controlled trial of low dose aspirin in the primary prevention of CHD in the over 70 s. Compliance was excellent at $87 \%$.

11 Harker LA, Boissel JP, Pilgrim AJ, et al. Comparative safety and tolerability of clopidogrel and aspirin: results from CAPRIE. CAPRIE steering committee and investigators. Clopidogrel versus aspirin in patients at risk of ischaemic events. Drug Saf 1999;21:325-35.

- This paper provides in detail the safety data from the CAPRIE trial. Discontinuation from the study because of adverse events was similar between aspirin $325 \mathrm{mg} /$ day and clopidogrel $75 \mathrm{mg} /$ day. The rates of neutropenia and thrombocytopenia were low. Overall the rate of haemorrhagic events was similar; however, clopidogrel treatment was associated with fewer vascular end points and gastrointestinal haemorrhages but more diarrhoea and rashes.

12 Rich MW. Therapy for acute myocardial infarction. Clin Geriatr Med 1996;12:141-68.

13 Dornbrook-Lavender KA, Roth MT, Pieper JA. Secondary prevention of coronary heart disease in the elderly. Ann Pharmacother 2003;37:1867-76.

- This review concentrated on the use of aspirin, $\beta$ blockers, ACE inhibitors, and statins in the secondary prevention of $\mathrm{CHD}$. It is a balanced report, up-to-date, and provides 48 useful references.

14 Gurwitz JH, Goldberg RJ, Chen Z, et al. Beta-blocker therapy in acute myocardial infarction: evidence for underutilization in the elderly. Am J Med 1992;93:605-10

15 Gruppo Italiano per lo Studio della Sopravvivenza nell 'infarto Miocardico. GISSI-3: effects of lisinopril and transdermal glyceryl trinitrate singly and together on 6-week mortality and ventricular function after acute myocardial infarction. Lancet 1994;343:1115-22.

16 Blood Pressure Lowering Treatment Triallist' Collaboration. Effects of different blood-pressure-lowering regimens on major cardiovascular events: results of prospectively designed overviews of randomized trials. Lancet 2003;362:1527-35

17 Staessen JA, Wang JG, Thijs L. Cardiovascular protection and blood pressure reduction: a meta-analysis. Lancet 2001;358:1305-15.

18 Gueyffier F, Bulpitt C, Boissel J-P, et al. Antihypertensive drugs in very old people: a subgroup meta-analysis of randomised controlled trials. Lancet 1999;353:793-6

19 Bulpitt CJ, Beckett NS, Cooke J, et al, on behalf of the Hypertension in the Very Elderly Trial (HYVET) Working Group. Results of the pilot study for the hypertension in the very elderly trial. $J$ Hypertens 2003;21:2409-17.

20 Heart Protection Study Collaborative Group. MRC/BHF heart protection study of cholesterol lowering with simvastatin in 20536 high risk individuals: a randomised placebo-controlled trial. Lancet 2002;360:7-22.

21 Shepard J, Blauw GJ, Murphy MB, el al. Pravastatin in elderly individuals at risk of vascular disease (PROSPER): a randomised controlled trial. Lance 2002;360:1623-30.

22 UK Prospective Diabetes Study (UKPDS) Group. Intensive blood-glucose control with sulphonylureas or insulin compared with conventional treatment and risk of complications in patients with type 2 diabetes (UKPDS 33). Lancet 1998:352:837-53.

23 UKPDS Group. UK prospective diabetes study 38: tight blood pressure control and risk of macrovascular and microvascular complications in type 2 diabetes (UKPDS 38) BMJ 1998;317:703-13.

24 Carroll K, Majeed A, Firth C, Gray J, et al. Prevalence and management of coronary heart disease in primary care: population-based cross-sectional study using a disease register. J Public Health Med 2003;25:29-35.

- This is a population study of 6778 patients with CHD in south west London. The diagnosis was confirmed in the medical records. The report is up-to-date with 30 references. 